\title{
Epidemiological and mortality analysis of older adults with HIV in eastern China
}

\author{
This article was published in the following Dove Press journal: \\ Clinical Interventions in Aging \\ 18 November 2013 \\ Number of times this article has been viewed
}

\section{Tiansheng $\mathrm{Xie}^{1,2}$ \\ Nanping $\mathrm{Wu}^{1,2}$}

'State Key Laboratory for Diagnosis and Treatment of Infectious Diseases, The First Affiliated Hospital of Zhejiang University, School of Medicine, Zhejiang University, ${ }^{2}$ Collaborative Innovation Center for Diagnosis and Treatment of Infectious Diseases, Hangzhou, People's Republic of China
Correspondence: Nanping Wu State Key Laboratory for Diagnosis and Treatment of Infectious Diseases, the First Affiliated Hospital of Zhejiang University, School of Medicine, Zhejiang University, 79 Qingchun Road, Hangzhou 3 I003I, People's Republic of China

Tel $+8657 \mid 87236580$

Fax +8657I 87236580

Emailflwnp@yahoo.com.cn
Objective: The aims of this study were to systematically review epidemiological characteristics in older people living with human immunodeficiency virus/acquired immunodeficiency syndrome (HIV/AIDS) (PLWHA) in low endemic areas of the People's Republic of China, analyze the causes of death and mortality, and provide a basis for targeted prevention in these populations.

Methods: Nine counties representative of the distribution and epidemiological factors of the HIV epidemic in Zhejiang Province were selected, and data from 1,115 HIV-positive individuals, including 196 older people ( $\geq 50$ years), who were confirmed as PLWHA from January 1 , 2000 to December 31, 2012, were retrospectively analyzed.

Results: The proportion of older PLWHA increased from $0 \%$ in 2000 to $22.45 \%$ in 2012 . Sexual transmission was the main route, accounting for $82.65 \%$ of infections in this group. Compared with the younger group (range from 14 to 49 years old), the older group had significantly lower CD4+ cell counts (291.64 versus 363.63; $P<0.001)$ when first diagnosed, and more of this group presented in the AIDS state with opportunistic infections $(51.02 \%$ versus $34.06 \%$; $P<0.001)$. In the older group, $25(12.76 \%)$ patients died directly of AIDS and $171(87.24 \%)$ were censored, and in the younger group 50 (5.44\%) patients died directly of AIDS and 869 (94.56\%) were censored. Estimated survival time since HIV diagnosis in the older group was $11.54 \pm 0.49$ years $(95 \%$ confidence interval [CI] 10.59-12.50), while in the younger group it was $13.85 \pm 0.46$ years (95\% CI 12.94-14.76), the log rank (Mantel-Cox) test gave a chi-square value of 3.83, and there was significant difference between the groups $(P<0.05)$.

Conclusion: The number of older PLWHA increased steadily over the study period in low HIV endemic provinces of a developing country. Later discovery and preexisting disease perhaps contributed to a shorter estimated survival time for older PLWHA and higher mortality.

Keywords: HIV, AIDS, older people, People's Republic of China, survival analysis

\section{Introduction}

Sex has been the main route of transmission of human immunodeficiency virus (HIV) for many years. Sexually transmitted infections predominantly affect younger age groups, ${ }^{1}$ and many people erroneously believe that HIV is a problem only for the young, both in terms of incidence and health problems. However, the global population is aging, and rapidly increasing numbers of people are living long, healthy, and potentially sexually active lives. ${ }^{2,3}$ With longer life expectancies and improvement in the quality of life, the sexual activity of older people has largely changed. Studies in sub-Saharan Africa indicated that approximately 3 million people were living with HIV in sub-Saharan Africa, and of the approximately 21 million people in sub-Saharan Africa aged $\geq 15$ years were people living with HIV/acquired immunodeficiency syndrome (AIDS) 
(PLWHA), among which $14.3 \%$ were $\geq 50$ years old. ${ }^{4}$ If treatment coverage continues to increase at present rates, the total number of HIV-infected people aged 50 years or older will nearly triple over the coming years: from 3.1 million in 2011 to 9.1 million in 2040.5 The older population of HIVinfected individuals in Australia has doubled from 12\%-14\% to $23 \%-28 \%$ in the past decade. ${ }^{6}$

To date, few studies on HIV have focused on people aged 50 and older, and these few studies mostly focused on developed countries. ${ }^{1,7-12}$ Also, there is an increasing amount of information on HIV among older adults in Africa. ${ }^{4,5,13,14}$ A number of sources, including demographic and health surveys, do not include mortality assessments among those aged 50 years or older and do not interview women older than 49 years of age. ${ }^{15}$ Still, there has been very little written about HIV among older adults in Asia.

In recent years, numbers of older AIDS patients have increased rapidly in the People's Republic of China. By the end of 2012, the proportion PLWHA in older people had already reached that seen in Europe and the USA 4 years ago. ${ }^{16}$ The differences between the People's Republic of China and Western countries in terms of local social and cultural attitudes, as well as different perceptions of sex and different behavior, all make older Chinese people at higher risk of HIV infection, and this situation is rarely reported. At the same time, the success of highly active antiretroviral therapy in prolonging life means that the average age of HIV-infected people living in resourcerich settings is increasing rapidly, ${ }^{17-20}$ making AIDS a chronic/ geriatric disease. It is likely that the aging AIDS population will show new epidemiological features.

To understand HIV among older adults in low endemic areas of the People's Republic of China, we collected information on PLWHA in nine counties of Zhejiang. The aim was to analyze the HIV epidemic and the related mortality in older PLWHA, so as to provide references for measures to reduce new HIV infection and mortality.

\section{Methods}

\section{Definition of older PLWHA}

Older adults were defined as individuals aged 50 years or older at the time of HIV/AIDS diagnosis. ${ }^{21}$

\section{Study setting and background}

Zhejiang is a coastal province located in eastern China, with a highly developed economy, cultural values of openness, a large migrant population (inflow mainly), and is rich in sexually transmitted infections risk factors, such as high prevalence of sexually transmitted infections and different entertainment venues distributed in the main urban areas at which female sex workers are employed. Zhejiang reported the first case of AIDS in the People's Republic of China in 1984, there were a reported 11,357 HIV infections at the end of 2012, and the HIV prevalence in the general population was about $0.01 \%$; while the infection level in the whole of the People's Republic of China was still low, and approximately one third of the provinces in the People's Republic of China have a similar HIV prevalence to Zhejiang. ${ }^{22}$ This study was conducted in the nine counties of Shaoxing, Tongxiang, Putuo, Xianju, Tonglu, Deqing, Anji, Wuxing, and Nanxun in Zhejiang Province. These nine counties account for $10 \%$ of the population of Zhejiang Province, with $10 \%$ of the reported PLWHA in the whole province. ${ }^{23}$

\section{Samples}

Zhejiang Province covers a population of 54.4 million, involving 90 counties, and in our sample system all of these counties were arranged by county HIV prevalence; the counties were divided into nine levels, each level with ten counties. Then random sample methods were used to choose one county in each level. In this way, nine counties were chosen, which were highly representative of the distribution of the HIV epidemic in Zhejiang province. Those given a diagnosis of PLWHA after the year of 2000, initially 1,153 individuals, were enrolled into this retrospective study. However, 38 people were excluded for the following reasons: short followup time; nonlocal first diagnosis; or severe lack of clinical data. The remaining 1,115, including 196 older patients, were included in further analysis. The study was approved by the Ethics Committee of The First Affiliated Hospital at the School of Medicine of Zhejiang University.

\section{Data sources}

The data were mainly collected from the the People's Republic of China Information System for Disease Control and Prevention from January 1, 2000 to December 31, 2012. The contents included general demographic characteristics, risk factors, route of transmission, follow-up time, and the date of death. Information concerning the diagnosis of death and the cause of death was obtained from the designated hospital of each county.

\section{Data analysis}

All data collected were input manually into a custom-designed database and analyzed using SPSS for Windows Version 16.0 (IBM Corporation, Armonk, NY, USA). Descriptive statistics were generated for each of the general characteristic variables. We used chi-square tests to compare the different age groups. Survival analysis for outcome variables was conducted using 
the log-rank test. Values of $P<0.05$ were considered statistically significant. Clinical outcomes for survival analysis were classified as "death as a direct result of AIDS" and "censored". We defined "censored" in this article as "lost to follow-up", "death, but not due to AIDS related disease", or "still alive when finished the cohort data collection".

\section{Results \\ Demographic data}

Of the 1,115 PLWHA included in the analysis, 196 (17.58\%) were $\geq 50$ years old, of whom $151(77.04 \%)$ were men and $45(22.96 \%)$ women. The average age was 59.06 years old, ranging from 50-84 years, and $60(30.61 \%)$ were aged 50-54 years. Most of them (123 cases, $62.76 \%$ ) were farmers; the proportion of migrant workers and those in commercial services in the $<50$ years old group was much higher than in the older group (44.83\% versus $17.34 \% ; P<0.001)$. Of the older group, 147 (75\%) were married; $132(67.35 \%)$ had only received 6 years of education or less; and most were native to Zhejiang, and were ethnic Han, in sharp contrast to the younger group, of whom nearly half were not native to Zhejiang (Table 1).

\section{Difference in epidemiological characteristics between older and younger groups}

The number of new diagnoses in older PLWHA showed a steady increasing trend since 2000: the proportion of older PLWHA in the whole HIV/AIDS population increased from $0 \%$ to $22.45 \%$ (44 cases) over this time period. A similar trend can be seen among heterosexuals: the proportion of older PLWHA in this population increased from $0 \%$ in 2000 to $28.68 \%$ (37 cases) in 2012 (Figure 1).

Compared with the $<50$ age group, PLWHA aged $\geq 50$ had a significantly lower number of CD4+ cells (mean value 291.64 versus $363.63 ; P<0.001$ ); a higher percentage of this group were found to have AIDS when first diagnosed (51.02 versus $34.06 \% ; P<0.001$ ). Of the older group, $162(82.65 \%)$ were infected through heterosexual transmission, a significantly higher proportion than in the $<50$ age group, while homosexual transmission and transmission via intravenous drug use were significantly lower. The survey also showed that the probability of high risk by nonmarital sexual behavior was significantly higher than in the younger group, and the probability exposed to needle sharing or engaging in homosexual behavior were significantly lower than in the younger group. Sexual transmission is the main route of infection for older PLWHA (183 cases, 93.36\%) (Table 2).
Table I Demographic characteristics of older and younger PLWHA

\begin{tabular}{|c|c|c|c|}
\hline & $\begin{array}{l}\geq 50(\mathrm{~N}=196) \\
\mathrm{n}(\%)\end{array}$ & $\begin{array}{l}<\mathbf{5 0}(\mathrm{N}=919) \\
\mathrm{n}(\%)\end{array}$ & $P$-value \\
\hline Gender & & & 0.16 \\
\hline Male & I5I (77.04) & $663(72.14)$ & \\
\hline Female & $45(22.96)$ & $256(27.86)$ & \\
\hline \multicolumn{4}{|l|}{ Age (years) } \\
\hline $50-54$ & $60(30.6 I)$ & & \\
\hline $55-59$ & $57(29.08)$ & & \\
\hline$\geq 60$ & $79(40.31)$ & & \\
\hline Occupation & & & $<0.001$ \\
\hline Farmer & $123(62.76)$ & $304(33.08)$ & \\
\hline Migration worker & 17 (8.67) & $229(24.92)$ & \\
\hline $\begin{array}{l}\text { Commercial service } \\
\text { provider }\end{array}$ & $17(8.67)$ & $183(19.91)$ & \\
\hline Other & $39(19.9)$ & $203(22.09)$ & \\
\hline Marital status & & & $<0.001$ \\
\hline Single & $9(4.59)$ & $323(35.15)$ & \\
\hline Married & I47 (75) & $466(50.7 \mathrm{I})$ & \\
\hline Divorced, widowed & $40(20.4 I)$ & $130(14.15)$ & \\
\hline Education & & & $<0.001$ \\
\hline Primary school or below & $132(67.35)$ & $366(39.83)$ & \\
\hline Junior school or above & $64(32.05)$ & $553(60.17 .84)$ & \\
\hline Residency & & & $<0.001$ \\
\hline Local county & $125(63.78)$ & $394(42.87)$ & \\
\hline Nonlocal county & $43(21.94)$ & $136(14.8)$ & \\
\hline in Zhejiang & & & \\
\hline Non-Zhejiang & $28(\mid 4.29)$ & $389(42.33)$ & \\
\hline Ethnicity & & & $<0.001$ \\
\hline Han & $194(98.98)$ & $787(85.64)$ & \\
\hline Other & $2(1.02)$ & $132(\mid 4.36)$ & \\
\hline
\end{tabular}

Abbreviation: PLWHA, people living with human immunodeficiency virus/acquired immunodeficiency syndrome; $\mathrm{N}$, number enrolled into group; n, number enrolled into subgroup.

\section{Cause of death and survival analysis}

In the $\geq 50$ age group, 34 patients $(17.35 \%)$ died during the study period, a significantly higher percentage than in the $<50$ age group $(9.14 \%)$. Univariate analysis of deathrelated risk factors in the older PLWHA showed that, compared with the CD4+ $>350$ group, the risk of death was greater in the CD4+ $<200$ and $200<$ CD4 $+<350$ groups (odds ratio $[\mathrm{OR}]=13.05,95 \%$ confidence interval $[\mathrm{CI}]$ 1.62-105.16, $P<0.05$; OR $=2.59$, 95\% CI 0.26-25.71, $P=0.42$, respectively). The same trend could also be seen in the $<50$ group $(\mathrm{OR}=44.96,95 \%$ CI $10.52-192.16, P<0.05$; OR $=5.57,95 \%$ CI $1.11-27.88, P<0.05$, respectively) (Table 3 ). In the $\geq 50$ age group, 25 patients (73.53\%) died of directly AIDS-related diseases, eight died of other diseases (non-AIDS), and one had an accidental death (Figure 2). In comparison, 50 patients $(61.90 \%)$ died of directly AIDSrelated diseases in the younger group, a slightly lower percentage than in the older group, 23 died of other diseases, and five died as a result of accident or suicide. There was a 


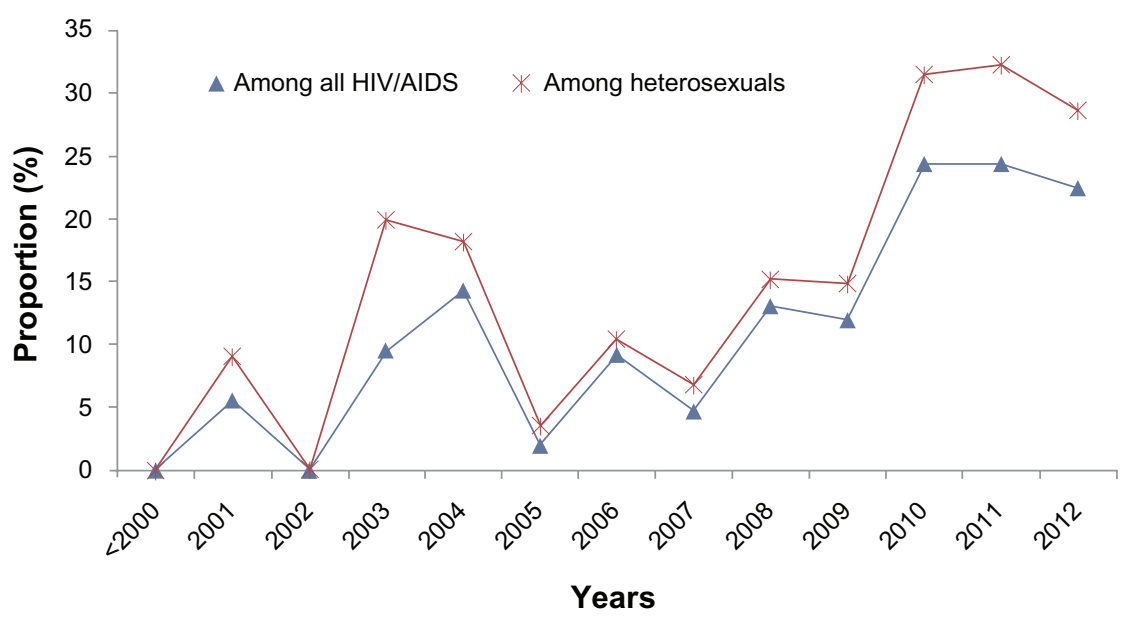

Figure I The proportion of PLWHA aged 50 years and above in the total and heterosexual HIVIAIDS populations.

Abbreviations: AIDS, acquired immunodeficiency syndrome; HIV, human immunodeficiency virus; PLWHA, people living with HIVIAIDS.

significant difference in the AIDS-related death rate between the two groups.

For survival analysis, 25 patients died directly of AIDS and 171 were censored in the older group, while in the younger group 50 patients died directly of AIDS and

Table 2 Epidemiological characteristics of older and younger PLWHA

\begin{tabular}{|c|c|c|c|}
\hline & $\begin{array}{l}\geq 50(N=196) \\
n(\%)\end{array}$ & $\begin{array}{l}<50(\mathrm{~N}=9 \mid 9) \\
\mathrm{n}(\%)\end{array}$ & $P$-value \\
\hline $\begin{array}{l}\text { CD4+ cells } / \mathrm{mm}^{3} \\
\text { at diagnosis }\end{array}$ & & & $<0.001$ \\
\hline$\leq 199$ & $54(32.14)$ & $133(19.44)$ & \\
\hline $200-349$ & 62 (36.9) & $196(28.65)$ & \\
\hline$\geq 350$ & $52(30.95)$ & $355(51.9)$ & \\
\hline $\begin{array}{l}\text { Stage of disease } \\
\text { at diagnosis }\end{array}$ & & & $<0.001$ \\
\hline HIV & $96(48.98)$ & $606(65.94)$ & \\
\hline AIDS & $100(51.02)$ & $313(34.06)$ & \\
\hline Route of transmission & & & $<0.001$ \\
\hline Heterosexual & $162(82.65)$ & $542(58.98)$ & \\
\hline Homosexual & $2 \mathrm{I}(\mathrm{I} 0.7 \mathrm{I})$ & I68 (I8.28) & \\
\hline Intravenous drug use & I $(0.5 \mathrm{I})$ & 91 (9.9) & \\
\hline Blood products & $9(4.59)$ & $38(4.13)$ & \\
\hline Other & $3(1.53)$ & 80 (8.7I) & \\
\hline Nonmarital sex & & & $<0.001$ \\
\hline \multicolumn{4}{|l|}{ in past year } \\
\hline Yes & $107(54.59)$ & $336(36.56)$ & \\
\hline No & $89(45.4 I)$ & $583(63.44)$ & \\
\hline Homosexual behavior & & & $<0.039$ \\
\hline \multicolumn{4}{|l|}{ in past year } \\
\hline Yes & $22(11.22)$ & $158(17.19)$ & \\
\hline No & 174 (88.78) & $76 I(82.8 I)$ & \\
\hline Sharing needles & & & $<0.001$ \\
\hline \multicolumn{4}{|l|}{ in past year } \\
\hline Yes & I $(0.5 \mathrm{I})$ & $63(6.86)$ & \\
\hline No & $195(99.49)$ & $856(93.14)$ & \\
\hline
\end{tabular}

Abbreviations: AIDS, acquired immunodeficiency syndrome; HIV, human immunodeficiency virus; PLWHA, people living with HIV/AIDS; N, number enrolled into group; $\mathrm{n}$, number enrolled into subgroup.
869 were censored. The resulting estimates of survival time since diagnosis were $11.54 \pm 0.49$ (95\% CI 10.59-12.50) in the older group and $13.85 \pm 0.46$ (95\% CI $12.94-14.76)$ in the younger group, the log-rank (Mantel-Cox) test chi-square value was 3.83 , and there was a significant difference between the two groups $(P<0.05)$ (Figure 3$)$.

\section{Discussion}

The number of older individuals living with HIV/AIDS is increasing, due to a growing number of new HIV diagnoses in this population as well as increased survival as a result of better management and treatment. Most studies on HIV and older adults in developing countries focus on the impact of HIV on economic and social roles, with little regard to the prevalence of HIV in older people or the direct impact of HIV infection on their health. ${ }^{24}$ Misconceptions remain common regarding older people and HIV. Health care professionals do not seem overly concerned with the possibility of HIV infection in older individuals, possibly because older people are less likely

Table 3 Factors associated with death in older and younger PLWHA

\begin{tabular}{|c|c|c|c|c|c|c|}
\hline & \multicolumn{3}{|c|}{$\geq 50(\mathrm{~N}=196)$} & \multicolumn{3}{|c|}{$<50(\mathrm{~N}=9 \mid 9)$} \\
\hline & OR & $95 \% \mathrm{Cl}$ & $P$-value & OR & $95 \% \mathrm{Cl}$ & $P$-value \\
\hline $\begin{array}{l}\text { CD4+ cells } / \mathrm{mm}^{3} \\
\text { at diagnosis }\end{array}$ & & & $<0.05$ & & & $<0.05$ \\
\hline$\leq 199$ & 13.05 & $\begin{array}{l}1.62 \\
105.16\end{array}$ & $<0.05$ & 44.96 & $\begin{array}{l}10.52 \\
192.16\end{array}$ & $<0.05$ \\
\hline $200-349$ & 2.59 & $\begin{array}{l}0.26 \\
25.71\end{array}$ & 0.42 & 5.57 & $\begin{array}{l}1.11 \\
27.88\end{array}$ & $<0.05$ \\
\hline$\geq 350$ & Ref & & & Ref & & \\
\hline
\end{tabular}

Abbreviations: $\mathrm{Cl}$, confidence interval; OR, odds ratio; PLWHA, people living with human immunodeficiency virus/acquired immunodeficiency syndrome; $\mathrm{N}$, number enrolled into group. 


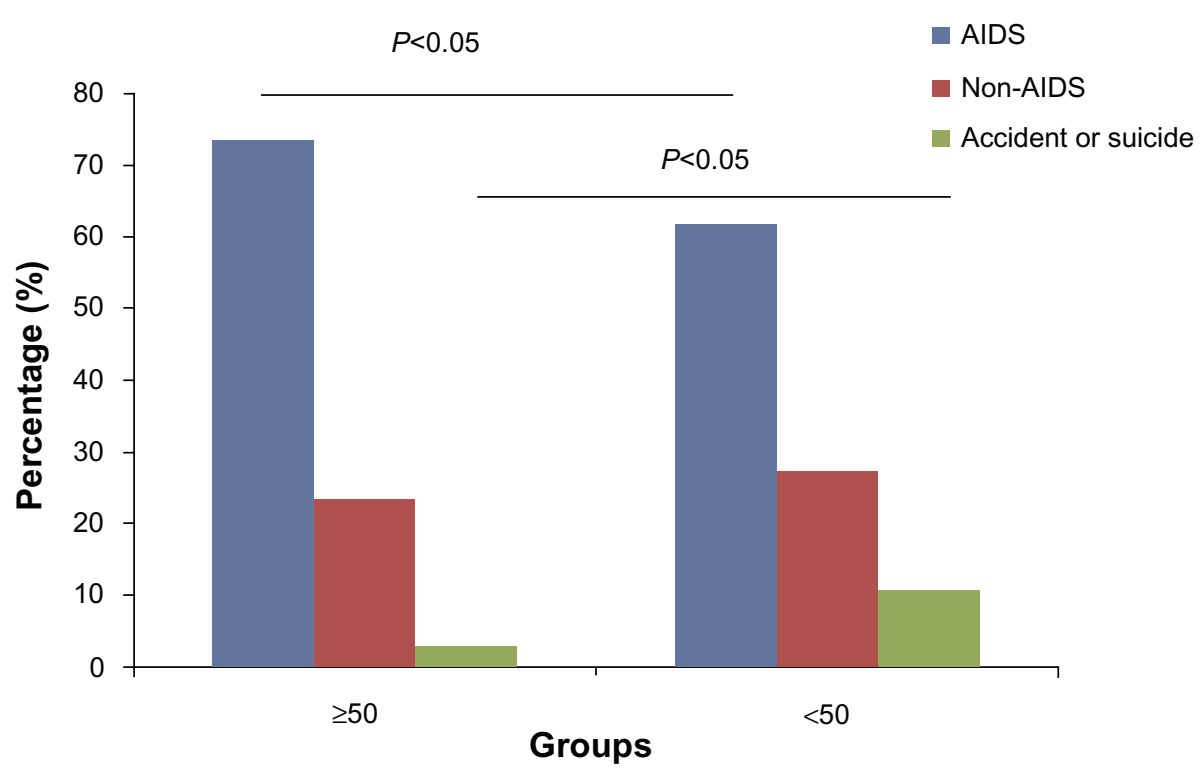

Figure 2 Analysis of the cause of death in older and younger PLWHA.

Abbreviations: AIDS, acquired immunodeficiency syndrome; HIV, human immunodeficiency virus; PLWHA, people living with HIVIAIDS.

than younger people to be considered sexually active or intravenous drug users.

In our study, the older PLWHA were mostly peasants with poor education, and most were Han people registered in Zhejiang. No difference was detected in gender proportion between the two groups; both were predominantly men.
The reason why the number of older adults and proportion of older adults living with HIV has increased might be that the sexual desires of older men often could not be satisfied by their wives, so they tend to seek commercial sex, and being poorly educated, peasants have poor awareness of self-protection. Moreover, for convenience and lower cost,

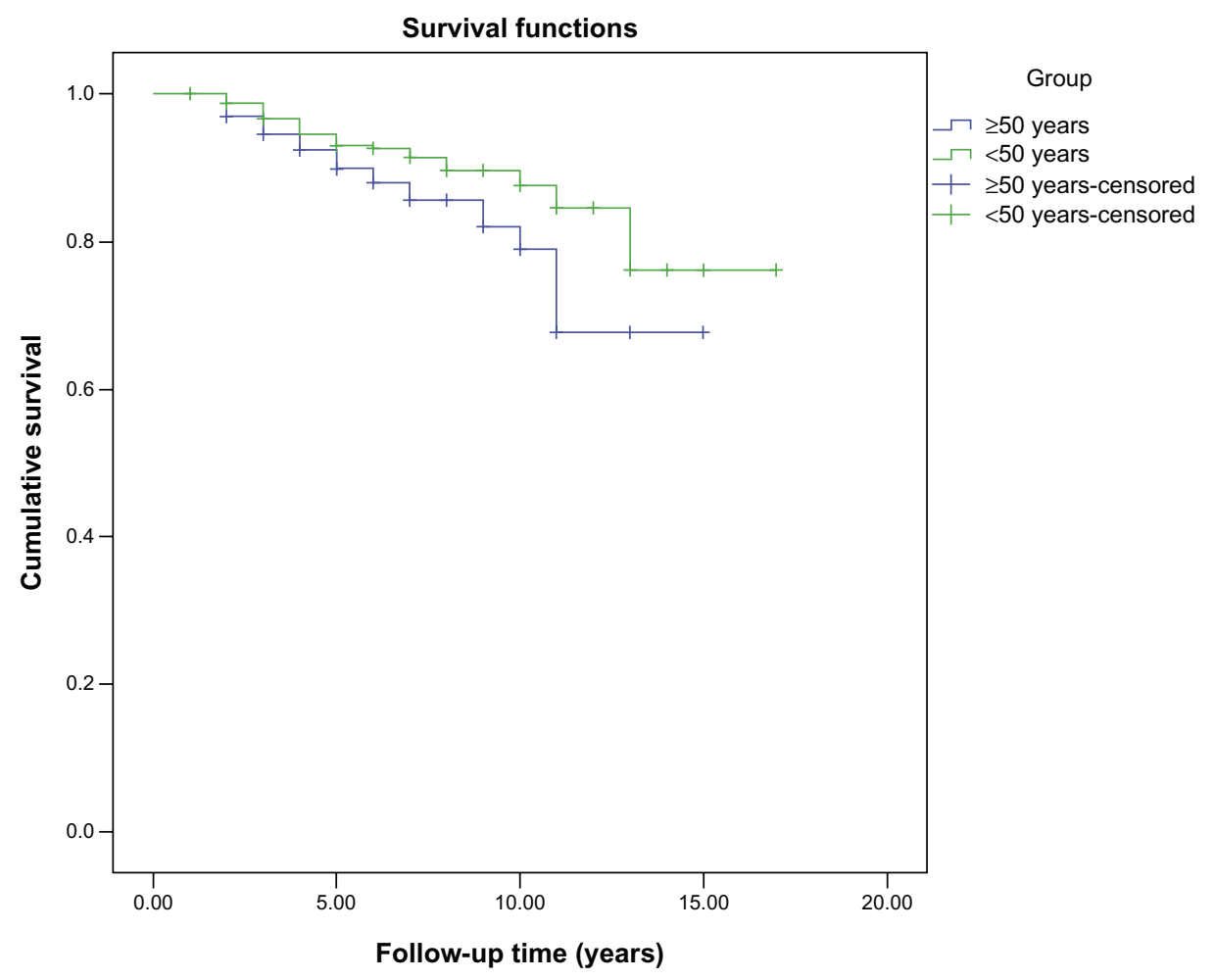

Figure 3 Survival analysis of PLWHA above and below the age of 50 years.

Abbreviation: PLWHA, people living with human immunodeficiency virus/acquired immunodeficiency syndrome. 
the elderly often choose low-level prostitutes, who have higher exposure risk for sexually transmitted infections. ${ }^{25}$ These factors mean that older men are exposed to risky, unprotected sex, significantly increasing the risk of HIV or other sexually transmitted infections. Notably, nonmarital sex in women is rarely reported; evidence indicates that they are mostly infected via their husbands. ${ }^{9,26}$ Also the Chinese government made efforts in HIV comprehensive prevention and control, expanded HIV testing coverage, and improved the understanding of HIV infection in the elderly, which also contributed to the big increase since 2005 in particular. ${ }^{27}$

In recent years, numbers of older PLWHA have steadily increased, especially since 2005: over this period the percentage of older PLWHA has increased almost six-fold. The rate of infection of older PLWHA by heterosexual transmission has also increased. This may be because HIV in Zhejiang is mainly sexually transmitted, and transmission in the older population consistently reflects the overall situation. In addition, many of the symptoms of HIV infection might be confused with signs of natural aging, such as weight loss, fatigue, and cognitive or visual problems. ${ }^{28}$ In this survey, it was found that young patients are mainly discovered by voluntary counseling and testing or provider-initiated HIV testing and counseling, while the older patients are mainly discovered passively. It was found that the numbers of CD4+ cells in older patients were significantly lower than in younger patients, and many of the older group were already presenting with manifestations of AIDS when found to be HIV-positive. Older people were diagnosed at later stages of HIV infection than younger individuals. ${ }^{29}$ The older patients themselves may also be less likely to suspect they have been infected with HIV. Most individuals diagnosed with HIV after age 60 never suspected that they were infected before they were tested. ${ }^{30}$ The risk factors identified in this study corroborate findings from similar studies on late diagnosis. ${ }^{31-35}$ We propose that more efforts should be undertaken to make screening for HIV and sexually transmitted infections by voluntary counseling and testing available to a wider age spectrum, and encourage universal HIV testing in the older general population.

Delayed diagnosis might partially explain some studies' findings of poorer clinical outcomes in older patients than in younger patients, including shorter intervals between the identification of HIV and the AIDS diagnosis, and reduced survival time. ${ }^{36} \mathrm{~A}$ survey on 12-, 24-, and 36-month survival after diagnosis showed that mortality was substantially higher among older patients at all three time points assessed. ${ }^{37}$ Analysis of the causes of death showed that most of the 34 deaths of AIDS patients in the older group were directly due to
AIDS-related diseases, a significantly higher proportion than in the younger group, whereas only eight of the 34 deaths were from non-AIDS-related diseases, which was unexpected. Older populations also experience high rates of mortality due to noncommunicable diseases such as cardiovascular disease or others. As has been reported elsewhere, such diseases are common even in rural areas of developing countries. ${ }^{38}$ However, the mortality rates from cardiovascular disease and diabetes in rural Kenya appear to be much lower than in rural India. ${ }^{39}$ It has been reported that elderly patients have a higher rate of non-AIDS-related deaths, but our study provided conflicting results, and this was suspected to be related to the patients being in later stages of AIDS when diagnosed. Meanwhile, their preexisting disease may also lead to the shortened life expectancy. Further exploration is necessary to investigate these factors in more detail. In order to combat the high mortality associated with late diagnosis, strategies must be put in place to encourage HIV testing. ${ }^{26}$ Some studies found higher adherence to antiretroviral therapy among patients aged $\geq 50$ years compared to younger patients, ${ }^{40,41}$ which suggests such an approach would be effective in this population.

In conclusion, we found the number of older PLWHA increased over the period of the study, with sexual transmission being the main route, emphasizing the pertinence of sexual education and intervention. The rate of death as a direct result of AIDS-related disease was higher in this group, and survival time was shorter in the older group than in the younger group; this may be due to the later diagnosis of HIV. We recommend the exploration of strategies to actively promote HIV screening in older people, so that we can discover and treat these patients earlier, and reduce AIDS mortality in this population.

\section{Acknowledgments}

We thank the Bureau of Health of Zhejiang Province, and the members of the Bureau of Health of the counties chosen in this study. This study was supported in part by grants from the MegaProject for National Science and Technology Development under the "11th and 12th, Five-Year Plan of the People's Republic of China" (2011ZX09302-003-03, 2013ZX10004-904). The funders had no role in study design, data collection and analysis, decision to publish, or preparation of the manuscript.

\section{Disclosure}

The authors report no conflicts of interest in this work.

\section{References}

1. Bodley-Tickell AT, Olowokure B, Bhaduri S, et al. Trends in sexually transmitted infections (other than HIV) in older people: analysis of data from an enhanced surveillance system. Sex Transm Infect. 2008;84(4): $312-317$. 
2. Poynten IM, Grulich AE, Templeton DJ. Sexually transmitted infections in older populations. Curr Opin Infect Dis. 2013;26(1):80-85.

3. Poynten IM, Templeton DJ, Grulich AE. Sexually transmissible infections in aging HIV populations. Sex Health. 2011;8(4):508-511.

4. Negin J, Cumming RG. HIV infection in older adults in sub-Saharan Africa: extrapolating prevalence from existing data. Bull World Health Organ. 2010:88:847-853.

5. Hontelez JA, de Vlas SJ, Baltussen R, et al. The impact of antiretroviral treatment on the age composition of the HIV epidemic in sub-Saharan Africa. AIDS. 2012:26 Suppl 1:S19-S30.

6. Murray JM, McDonald AM, Law MG. Rapidly ageing HIV epidemic among men who have sex with men in Australia. Sex Health. 2009;6(1):83-86.

7. Bhavan KP, Kampalath VN, Overton ET. The aging of the HIV epidemic. Curr HIV/AIDS Rep. 2008;5(3):150-158.

8. Elford J, Ibrahim F, Bukutu C, Anderson J. Over fifty and living with HIV in London. Sex Transm Infect. 2008;84(6):468-472.

9. Kyobutungi C, Ezeh AC, Zulu E, Falkingham J. HIV/AIDS and the health of older people in the slums of Nairobi, Kenya: results from a cross sectional survey. BMC Public Health. 2009;9:153.

10. Navarro G, Nogueras MM, Segura F, et al; PISCIS Study Group HIV-1 infected patients older than 50 years. PISCIS cohort study. J Infect. 2008;57(1):64-71.

11. Nguyen N, Holodniy M. HIV infection in the elderly. Clin Interv Aging. 2008;3(3):453-472.

12. Schmid GP, Williams BG, Garcia-Calleja JM, et al. The unexplored story of HIV and ageing. Bull World Health Organ. 2009;87(3):162-162A.

13. Nyirenda M, Chatterji S, Rochat T, Mutevedzi P, Newell ML. Prevalence and correlates of depression among HIV-infected and -affected older people in rural South Africa. J Affect Disord. 2013;151(1):31-38.

14. Nyirenda M, Newell ML, Mugisha J, et al. Health, wellbeing, and disability among older people infected or affected by HIV in Uganda and South Africa. Glob Health Action. 2013;6:19201.

15. Central Statistical Agency [Ethiopia] and ORC Macro. Ethiopia Demographic and Health Survey 2005. Addis Ababa, Ethiopia and Calverton, MD, USA: Central Statistical Agency and ORC Macro; 2006. Available from: http://www.measuredhs.com/pubs/pdf/FR179/ FR179[23June2011].pdf. Accessed October 10, 2013.

16. Tucker JD, Wong FY, Nehl EJ, Zhang F. HIV testing and care systems focused on sexually transmitted HIV in China. Sex Transm Infect. 2012;88(2):116-119.

17. Hart GJ, Elford J. Sexual risk behaviour of men who have sex with men: emerging patterns and new challenges. Curr Opin Infect Dis. 2010;23(1):39-44.

18. Luther VP, Wilkin AM. HIV infection in older adults. Clin Geriatr Med. 2007;23(3):567-583, vii.

19. Lyons A, Pitts M, Grierson J, Thorpe R, Power J. Ageing with HIV: health and psychosocial well-being of older gay men. AIDS Care. 2010;22(10):1236-1244

20. Manfredi R, Calza L. HIV infection and AIDS in advanced age Epidemiological and clinical issues, and therapeutic and management problems. Infez Med. 2004;12(3):152-173. Italian.

21. Longo B, Camoni L, Boros S, Suligoi B. Increasing proportion of AIDS diagnoses among older adults in Italy. AIDS Patient Care STDS 2008;22(5):365-371.

22. Bureau of Health of Zhejiang Province (2012) Zhejiang province reported the latest HIV/AIDS epidemic. Available at http://health.zjol. com.cn/05zjhealth/system/2012/12/01/018986090.shtml. Chinese.

Clinical Interventions in Aging

\section{Publish your work in this journal}

Clinical Interventions in Aging is an international, peer-reviewed journal focusing on evidence-based reports on the value or lack thereof of treatments intended to prevent or delay the onset of maladaptive correlates of aging in human beings. This journal is indexed on PubMed Central, MedLine, the American Chemical Society's 'Chemical Abstracts
23. Zhejiang Provincial Government. Population statistics 2010. Hangzhou: Zhejiang Provincial Government; 2012. Available from: http://www. zj.stats.gov.cn/art/2007/12/17/art_42_821.html. Accessed October 20,2013. Chinese.

24. Williams N, Knodel J, Kiry Kim S, Puch S, Saengtienchai C. Overlooked potential: older-age parents in the era of ART. AIDS Care. 2008;20(10):1169-1176.

25. Pearline RV, Tucker JD, Yuan LF, et al. Sexually transmitted infections among individuals over fifty years of age in China. AIDS Patient Care STDS. 2010;24(6):345-347.

26. Iwuji CC, Churchill D, Gilleece Y, Weiss HA, Fisher M. Older HIVinfected individuals present late and have a higher mortality: Brighton, UK cohort study. BMC Public Health. 2013;13:397.

27. Shen J, Yu DB. Governmental policies on HIV infection in China. Cell Res. 2005:15(11-12):903-907.

28. Sanders GD, Bayoumi AM, Holodniy M, Owens DK. Cost-effectiveness of HIV screening in patients older than 55 years of age. Ann Intern Med. 2008;148(12):889-903.

29. Orchi N, Balzano R, Scognamiglio P, et al; SENDIH group. Ageing with HIV: newly diagnosed older adults in Italy. AIDS Care. 2008;20(4): 419-425.

30. Abel T, Werner M. HIV risk behaviour of older persons. Eur J Public Health. 2003;13(4):350-352.

31. Begovac J, Gedike K, Lukas D, Lepej SZ. Late presentation to care for HIV infection in Croatia and the effect of interventions during the Croatian Global Fund Project. AIDS Behav. 2008;12(Suppl 4):S48-S53.

32. Lanoy E, Mary-Krause M, Tattevin P, et al; ANRS C004 French Hospital Database on HIV Clinical Epidemiological Group. Frequency, determinants and consequences of delayed access to care for HIV infection in France. Antivir Ther. 2007;12(1):89-96.

33. Sabin CA, Smith CJ, Gumley H, et al. Late presenters in the era of highly active antiretroviral therapy: uptake of and responses to antiretroviral therapy. AIDS. 2004;18(16):2145-2151.

34. Smith RD, Delpech VC, Brown AE, Rice BD. HIV transmission and high rates of late diagnoses among adults aged 50 years and over. AIDS. 2010;24(13):2109-2015.

35. Wolbers M, Bucher HC, Furrer H, et al; Swiss HIV Cohort Study. Delayed diagnosis of HIV infection and late initiation of antiretroviral therapy in the Swiss HIV Cohort Study. HIV Med. 2008;9(6):397-405.

36. Lazarus JV, Nielsen KK. HIV and people over 50 years old in Europe. HIV Med. 2010;11(7):479-481.

37. Centers for Disease Control and Prevention. HIV surveillance report. Atlanta: Centers for Disease Control and Prevention. Available from: http://www.cdc.gov/hiv/surveillance/resources/ reports/2008report/2008. Accessed October 20, 2013.

38. Gill GV, Mbanya JC, Ramaiya KL, Tesfaye S. A sub-Saharan African perspective of diabetes. Diabetologia. 2009;52(1):8-16.

39. Joshi R, Cardona M, Iyengar S, et al. Chronic diseases now a leading cause of death in rural India - mortality data from the Andhra Pradesh Rural Health Initiative. Int J Epidemiol. 2006;35(6):1522-1529.

40. Hinkin CH, Hardy DJ, Mason KI, et al. Medication adherence in HIVinfected adults: effect of patient age, cognitive status, and substance abuse. AIDS. 2004;18 Suppl 1:S19-S25.

41. Silverberg MJ, Leyden W, Horberg MA, DeLorenze GN, Klein D, Quesenberry CP. Older age and the response to and tolerability of antiretroviral therapy. Arch Intern Med. 2007;167(7):684-691.

Service' (CAS), Scopus and the Elsevier Bibliographic databases. The manuscript management system is completely online and includes a very quick and fair peer-review system, which is all easy to use. Visit http://www.dovepress.com/testimonials.php to read real quotes from published authors. 